\title{
Régimen alimenticio y nutrición en algunos hatos del Alto Apure (Venezuela): Un estudio cuantitativo, 1909-1910
}

\author{
Jaime Torres Sánchez. \\ Universidad de los Andes. San Cristóbal, Venezuela
}

Se examinan algunos caracteres de la actividad de trabajo y del régimen alimenticio de los peones de un grupo de hatos del Alto Apure, cuyo propietario era el presidente de Venezuela, Juan Vicente Gómez. La construcción de la ración media permite sostener que presentaba un adecuado nivel calórico y que su calidad nutricional podría haber estado reducida a los mínimos exigibles para la manutención del nivel de actividad en el trabajo del llano. Es posible que las características del funcionamiento económico de los hatos estudiados presionaran los costos de alimentación.

La monotonía de la dieta podría haber sido garantía de equilibrio nutricional, al combinarse con actividades personales de caza y pesca, de tal modo que la estacionalidad en el empleo de la mano de obra aparece como una condición de supervivencia.

Este artículo presenta algunos resultados de un estudio sobre la alimentación de los trabajadores de un conjunto de hatos del Alto Apure, que pasaron a ser propiedad encubierta de Juan Vicente Gómez a fines del primer decenio del siglo XX. ${ }^{1}$ Ubicados en esa región del Estado Apure, entre los ríos Uribante por el norte y Sarare por el sur, desde la confluencia de éstos por el este hasta la Selva de San Camilo por el oeste, orientaban su actividad al mercado de San Cristóbal, capital del Estado Táchira y eje del desarrollo cafetalero exportador venezolano hacia 1910 (ver mapa). El hato de mayor valor y tamaño era 'El Caimán', donde se concentraba la gestión. Situado en una extensa área de pastizales en el piedemonte andino, estaba cruzado de oriente a occidente por un antiguo camino ganadero que, a través de la Selva de San Camilo, unía Guasdualito con San Cristóbal. Guasdualito era un poblado ubicado en la margen occidental del Sarare, a pocos kilómetros de su confluencia con el Uribante, y era tanto el punto de

1 Juan Vicente Gómez es el fundador del Estado Moderno en Venezuela. En 1910 los bienes de Celestino Castro, ex-presidente del Estado Táchira y hermano de Cipriano Castro - ex-presidente de Venezuela - salieron a remate evaluados en Bs. 520.700. Sus hatos fueron comprados en Bs. 90.000 por Juan V. Gómez, ya presidente de la República, por interpósita persona. En: Registro Principal de San Cristóbal (en adelante RPSC), Civil, 1910, Ejecución seguida por el Gobierno Nacional contra los bienes del general Celestino Castro, fs. 50-55 v. En 1906 el valor del total de propiedades agropecuarias de J. V. Gómez en el Estado Apure era de Bs. 1.829.388, Troconis G., Luis: La cuestión agraria en la historia nacional, Caracas, 1962, pág. 138. 
JAIME TORRES SÁNCHEZ
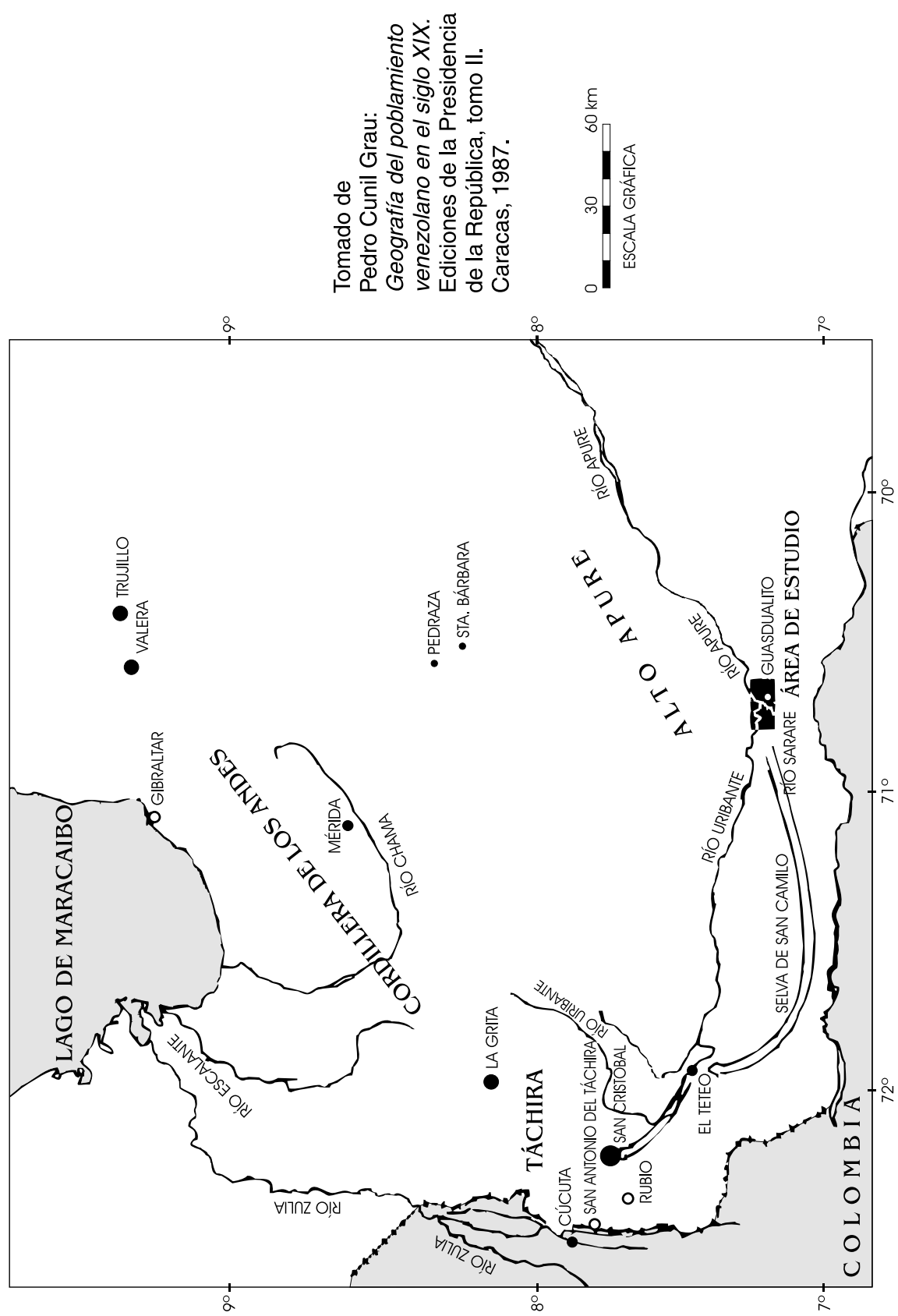
convergencia del ganado del Bajo Apure destinado a la exportación, como el mayor polo comercial de la región llanera sur-occidental.

Según el cuadro 1 , los dos primeros hatos constituían el núcleo del complejo pecuario, que tenía en total una masa ganadera potencial de 9.600 reses. El total real pudo haber fluctuado entre 7.000 y 9.940 y la producción anual entre 600 y 800 animales, respectivamente. Es probable que la producción efectiva estuviera más cercana al primer valor, pues no todas las superficies consideradas eran de pastizales.

\section{CUADRO 1}

INDICADORES ECONÓMICOS DE LOS HATOS DE J. V. GÓMEZ EN EL ALTO APURE (1904)

\begin{tabular}{lcccc} 
& \multicolumn{2}{c}{ ÁREA } & VALOR & NÚM. DE RESES \\
\cline { 2 - 3 } Nombre & Leguas & Hectáreas & \multicolumn{1}{c}{ Bs } & (potenciales) \\
\hline El Caimán & 8 & 20.000 & 72.000 & 3.200 \\
La Balza & 4 & 10.000 & & 1.600 \\
Mendero & 2 & 5.000 & 48.000 & 800 \\
Las Margaritas & 4 & 10.000 & 30.000 & 1.600 \\
Comunidad de San Camilo & 6 & 15.000 & 50.000 & 2.400 \\
\hline TotAL & 24 & 60.000 & 200.000 & 9.600
\end{tabular}

El valor sumado de 'La Balza' y de 'Mendero' es de 48.000 bolívares.

Fuente: RPSC, Civil, 1910, fs. 39-40, 50-55.

Tal concentración de propiedades en un solo dueño la convertía en una gran explotación dentro de las grandes propiedades de los llanos centrooccidentales, aunque no de las mayores. ${ }^{2}$ Para el conjunto del área llanera se sabe que a comienzos del siglo XX las remuneraciones en los hatos eran por tarea realizada - 'ajuste' o destajo- o por tiempo de trabajo. Probablemente la remuneración diaria por tareas se equiparaba a la del trabajo por

2 Calzadilla V., Fernando: Por los llanos de Apure, Caracas, 1948, pág. 158, estima la cosecha anual de un hato bien trabajado entre 1.000 y 2.000 novillos. Sus parámetros, cosechas y promedio de reses por hato son válidas hasta 1910. Para 1920 algunos datos indicarían que en los distritos Muñoz y Páez, que abarcaban el Alto Apure, un total de 56 hatos tenían más de diez mil reses cada uno y 14 de ellos, unas catorce mil reses en promedio. Para los datos básicos, ver: Boletín de la Cámara de Comercio de Caracas, año IX, 15 de agosto de 1920, núm. 81. 
jornada, en condiciones normales. La contratación por ajuste habría sido más frecuente en los 'peones de mano' y su remuneración en dinero no incluía alimentación y albergue. Para los 'peones de a caballo' lo usual habría sido la cancelación semanal o mensual por días de trabajo. ${ }^{3}$ Los hatos estudiados participan de estos caracteres en las formas de remuneración.

CUADRO 2

REMUNERACIÓN DE LA MANO DE OBRA: OCTUBRE (1909) - MAYO (1910)

\begin{tabular}{lrrrrrr} 
& \multicolumn{4}{c}{ POR DÍA } & & \\
\cline { 2 - 4 } & Peones de hato & Otros & Sub-total & POR TAREA & TOTAL \\
\hline Núm. de hombres & 48 & 27 & 75 & 44 & 119 \\
Núm. de días de trabajo & 1.351 & 741,5 & $2.092,5$ & 111,0 & $2.203,5$ \\
Salarios & $\$ 698,2$ & $\$ 354,5$ & $\$ 1.052,7$ & & $\$ 387,6$ & $\$ 1.440,4$
\end{tabular}

Fuente: Tabla I.

Los valores tienen cierto margen de error para la variable 'número de hombres', ya que varios trabajos por tarea eran realizados por una misma persona. Los porcentajes de días de trabajo y de salarios, en cambio, son más exactos. De ellos se desprende que el $65 \%$ del tiempo trabajado fue 'por día' y los pagos 'por tarea' fueron minoritarios. Los peones de 'a caballo' eran remunerados por día, al igual que otros tipos de trabajadores, como meseros, sirvientes, canoeros y pastores de marranos. Todos los trabajadores de este tipo tenían acceso a la alimentación.

En el cuadro 3 se presentan datos para el análisis de la estructura del consumo, en la que los dos primeros totales corresponderían virtualmente a hipótesis de consumo mínimo y máximo de 'Carne' (hipótesis I y II), respectivamente, de acuerdo a las dos bases de 'carne utilizable', cálculo basado en el peso por animal característico del Alto Apure. El total III corresponde a la hipótesis III de consumo de carne basada en un peso de 14 arrobas por res. La ración calculada para un trabajador medio se compone de alimentos frescos, algunos ya cocidos pero sin ingerir. En las rutinas alimenticias nunca faltaba una comida diaria abundante, aunque había variabilidad respecto al desayuno.

3 Carvallo, Gastón: El hato venezolano. 1900-1980, Caracas, 1964, págs. 33-34. 
RÉGIMEN ALIMENTICIO Y NUTRICIÓN EN HATOS DEL ALTO APURE

CuAdRo 3

COMPOSICIÓN DE NUTRIENTES DE LA RACIÓN MEDIA DIARIA:

OCTUBRE (1909) - MAYO (1910)

\begin{tabular}{|c|c|c|c|c|}
\hline ALIMENTOS & CALORÍAS & $\begin{array}{l}\text { PRÓTIDOS } \\
\text { grs. }\end{array}$ & $\begin{array}{c}\text { LÍPIDOS } \\
\text { grs. }\end{array}$ & $\begin{array}{c}\text { GLÚCIDOS } \\
\text { grs. }\end{array}$ \\
\hline Café & 8,51 & 1,2767 & 0,4256 & 3,4046 \\
\hline Especias & - & - & - & - \\
\hline Arroz & 128,90 & 2,5549 & 0,1161 & 28,3357 \\
\hline Cebollas & 4,50 & 0,1501 & 0,0214 & 1,1042 \\
\hline Aceite & 7,38 & - & 0,8400 & - \\
\hline Manteca & 449,47 & 一 & 49,8300 & - \\
\hline Carne (I) & 406,34 & 58,2414 & 17,6079 & - \\
\hline Carne (II) & 637,22 & 91,3342 & 27,6127 & - \\
\hline Carne (III) & 495,62 & 71,0382 & 21,4767 & - \\
\hline Panela & 623,49 & 1,0510 & - & 161,1288 \\
\hline Plátano & 630,17 & 6,4400 & 0,9200 & 167,4330 \\
\hline Maíz & $2.989,90$ & 74,5300 & 35,0600 & 619,0400 \\
\hline Ajos & 4,20 & 0,2000 & 0,0080 & 1,0280 \\
\hline Frijoles & 6,00 & 0,4280 & 0,0208 & 1,0231 \\
\hline Topochos & 108,30 & 1,2700 & 0,9800 & 26,8290 \\
\hline TOTAL (I) & $5.367,20$ & 146,1400 & 105,8300 & $1.009,3300$ \\
\hline TOTAL (II) & $5.598,00$ & 179,2390 & 115,8300 & $1.009,3300$ \\
\hline TOTAL (III) & $5.456,40$ & 109,6900 & 109,6900 & $1.009,3300$ \\
\hline
\end{tabular}

Fuente: Tabla II.

Para el Alto Apure se ha señalado que en algunas ocasiones el 'trabajo de llano' se iniciaba sólo con un pocillo de café y en otras regiones había un desayuno abundante. ${ }^{4}$ En los meses considerados había períodos de inactividad ganadera, en los cuales la comida diaria pudo haber sido más pobre en cantidad que en los períodos de trabajo máximo. La alimentación en el hato pudo haber sido distinta a la comida familiar, pero puede suponerse que esas variaciones no fueron sustanciales, dadas las determinaciones ecológicas sobre la agricultura de subsistencia, pues no debe descartar-

4 Calzadilla V.: Por los llanos..., págs. 20, 144-145, 258-259. Hernández, Lázaro: Tiempos idos en el Alto Apure, Cumaná, 1980, págs. 41-47. 
se la posibilidad de que esta última cocina cumpliera ciertas funciones de equilibrio nutricional.

Los datos indicarían que el régimen alimenticio giraba en torno a muy pocos productos básicos: maíz, plátanos, topochos y panela, que eran producidos en los hatos y aportaban el $81 \%$ y el $77,7 \%$ de las calorías totales, en las hipótesis I y II de la ración disponible neta, respectivamente. El maíz proporcionaba el grueso de las calorías, $55,7 \%$ y 53,4\%, en ambas hipótesis. Llama la atención el carácter básicamente vegetal de la ración, que contrasta tanto con la naturaleza ganadera de las actividades, como con las observaciones contemporáneas que atribuían un predominio cárnico al régimen de alimentación. A comienzos de siglo, observadores de las costumbres en dicha área señalaban: "la comida del llanero se basaba en carne de ganado, alguna de caza y escasamente pescado. También se contaba con la yuca, el plátano, el topocho, casabe, pero lo esencial en la dieta era la carne de ganado en las diferentes variedades que el mismo medio proporciona". ${ }^{5}$ Esta fuente cita muchas frutas silvestres que se comían y algunas pocas frutas que era necesario sembrar, dentro de un cuadro alimenticio muy poco variado. Hacia 1935, todavía en 'El Caimán' persistían estas características y seguían siendo habituales estos productos: carne , plátano, maíz, yuca, queso, panela y café. La leche era escasa, y agregarla al café se consideraba propio de los "consentidos de la casa". ${ }^{6}$ Se comía carne todos los días y el café era habitual pero no se consumía fruta. Según el observador, no había fruta silvestre y los hombres dependían enteramente de la comida del hato. En éste se fabricaba el queso para el consumo y a los peones se les "picaba un queso en la mesa" cada día.

Se puede afirmar que los rasgos principales del régimen alimenticio no habían variado desde comienzos del siglo XIX: ausencia de leche en la dieta adulta, importancia social de la carne, poca verdura y presencia de ciertos artículos básicos como arroz, panela, plátanos y maíz. Poco se sabe respecto a la introducción del café como bebida en los Llanos, pero es probable que su presencia predominante datara de la segunda mitad del siglo, pues hasta mediados de la centuria era corriente en esa región la yerba mate

5 Hernández: Tiempos idos..., págs. 53 y 64.

6 Julio César Rojas, peón de El Caimán hacia la década del treinta, según entrevista en Guasdualito, 15 de junio de 1986.

7 Páez, Ramón: Escenas rústicas en Sur América o la vida en los Llanos de Venezuela, Caracas, 1973, págs. 47-48, señala el menosprecio del llanero por la leche y la mantequilla, el predominio de la carne y el consumo de café en la mañana a mediados del siglo XIX. Para la segunda mitad de ese siglo insiste en el predominio de la carne Appun, Karl: En los trópicos, Caracas, 1961, pág. 221. 
como una bebida de mujeres. ${ }^{8}$ Así, parece que la monotonía en la alimentación de los hatos fue una característica de larga duración, aun cuando las observaciones históricas son escasas.

Aún más, tal régimen de alimentos parece adaptarse a los caracteres de la alimentación advertidos en la Venezuela del último tercio del siglo XIX, en la medida en que reproduce la débil importancia de la carne y la fuerte presencia del plátano, maíz y papelón en la aportación calórica, ${ }^{9}$ aunque revela una mayor significación relativa del aporte cárnico.

Es posible examinar la estructura de la ración media, es decir, analizar comparativamente la densidad de nutrientes que ella presenta para establecer su calidad relativa. Con ello surge el problema de la importancia analítica de los sistemas de referencia interpretativos para el examen de los datos..$^{10} \mathrm{Al}$ tenor de experiencias metodológicas en historia de la alimentación se puede intentar una evaluación que considere los requerimientos nutricionales contemporáneos. ${ }^{11}$

En el cuadro 4 la comparación se ha hecho respecto a los requerimientos actuales para realizar una faena "Muy activa" y "Excepcionalmente activa" en un grupo de edad que pudo haber correspondido al de los trabajadores de los dos hatos. El estándar de comparación es un hombre-tipo de edad entre 20 y 39 años, con un peso de $66 \mathrm{~kg}$, sano, físicamente apto para un trabajo 'muy activo' de ocho horas diarias y que consume alimentos para un gasto energético medio de $3.564 \mathrm{kcal} / \mathrm{día}$. Considerados los requerimientos calóricos para un trabajo 'excepcionalmente activo', esta última cifra se situaría en 4.092 .

La cantidad total de calorías disponibles en la ración de estos hatos, 5.367 y 5.598 para ambas hipótesis, era satisfactoria para el nivel de desempeño físico. Si se considera que la dificultad principal en un análisis

8 Era "preferida por las mujeres suramericanas mucho más que el té y aun el chocolate" según Vawell, Richard: Las sabanas de Barinas, Caracas, 1973, pág. 91. Hacia 1857 el café parecía una bebida habitual en los Llanos Centrales según Rosti, Pal: Memorias de un viaje por América, Caracas, 1968, págs. 170 y 183. En las haciendas jesuíticas del Casanare en el siglo XVIII el café no era parte de la dieta según advierte Raush, Jane M.: Una frontera de la sabana tropical. Los llanos de Colombia. 1531-1831, Bogotá , 1994, págs. 275 y 282.

9 Torres S., Jaime: "Consumo de carne y nutrición. Aspectos de su evolución histórica en Venezuela: 1609-1873", Anuario de Estudios Americanos, LIV, I, Sevilla, enero-junio de 1997, pág. 65, cuadros 2 y 3 .

10 Aymard, M.: "Pour l'histoire de l'alimentation: quelques remarques de methode", Annales, núms. 2-3, Paris, Mars-Juin, 1985, págs. 431-444.

11 Instituto Nacional de Nutrición: Requerimientos de energía y de nutrientes de la población venezolana, Documento provisional, núm. 45, Caracas, 1985. 
histórico reside en la homologación de niveles de intensidad de trabajos situados en contextos sociales distintos, esta conclusión podría fundamentarse más aún. Los rasgos del 'trabajo de llano' hacia el primer decenio del siglo XX, exigían un desgaste físico en los períodos de 'cosecha' que, posiblemente, no se encuentra ni siquiera en el trabajo en áreas llaneras actuales, dentro de hatos que pudieran considerarse similares. ${ }^{12}$ De tal modo que podría no ser todavía adecuada, como base comparativa, la categoría 'excepcionalmente activo', utilizada hoy para clasificar el trabajo de un cierto porcentaje del personal obrero de la rama económica de 'Hidrocarburos, Minas y Canteras'. En todo caso, en el llano había actividades estacionales que no eran tan exigentes, con lo que la selección de las categorías no parecería ser inadecuada. Pero debe considerarse la posibilidad de sesgo por subvaloración de la intensidad del trabajo llanero a comienzos del siglo.

\section{Cuadro 4}

\section{COMPARACIÓN DE LA RACIÓN MEDIA CON REQUERIMIENTOS ACTUALES PARA UN GRUPO DE EDAD DE 20-39 AÑOS}

\begin{tabular}{|c|c|c|c|c|c|}
\hline \multirow[b]{2}{*}{ NUTRIENTES } & \multicolumn{2}{|c|}{$\begin{array}{l}\text { DISPONIBILIDAD } \\
(1909-1910)\end{array}$} & \multirow{2}{*}{$\begin{array}{c}\text { REQUERIMIENTOS } \\
\text { POR } 1000 \mathrm{kcal}\end{array}$} & \multicolumn{2}{|c|}{$\begin{array}{c}\text { INQ. } \\
(1909-1910)\end{array}$} \\
\hline & Hip. I & Hip. II & & Hip. I & Hip. II \\
\hline Proteínas (g) & 27,20 & 32,00 & 20,0 & 1,4 & 1,6 \\
\hline Calcio $\quad(\mathrm{mg})$ & 92,30 & 90,10 & 150,0 & 0,6 & 0,6 \\
\hline Hierro & 9,10 & 9,40 & 3,0 & 3,0 & 3,1 \\
\hline Vit. A & 214,70 & 205,90 & 250,0 & 0,9 & 0,8 \\
\hline Tiamina (mg) & 0,76 & 0,75 & 0,4 & 1,9 & 1,9 \\
\hline Ribof. & 0,39 & 0,45 & 0,6 & 0,7 & 0,8 \\
\hline Niacina (mg) & 9,11 & 10,10 & 6,8 & 1,3 & 1,5 \\
\hline Vit. C (mg) & 11,60 & 11,10 & 10,0 & 1,2 & 1,1 \\
\hline
\end{tabular}

Fuente: Tabla II y III; Instituto Nacional de Nutrición: Requerimientos de energía y de nutrientes de la población venezolana, núm. 45, Caracas, 1985.

12 Cronistas señalan el excepcional esfuerzo físico que demandaba el 'trabajo de llano'. Según análisis actuales, atletas de entrenamiento aeróbico intenso pueden requerir de 4.000 a $6.000 \mathrm{kcal}$ diarias o más. Ver Mahan, J. K y Arlin, M. T.: Krauze: Nutrición y Dietoterapia, México, 195, pág. 353. 
De acuerdo al 'índice de calidad nutricional', INQ, la estructura de la dieta del cuadro anterior revela que la ración media, antes de ser preparada y consumida, contenía nutrientes en cantidades adecuadas de proteínas, hierro, tiamina, niacina y vitamina C. Era insuficiente en vitamina A y riboflavina. De un modo general, podría concluirse que ésta era una dieta satisfactoria. ${ }^{13}$

Siendo importante el análisis del régimen alimentario tanto en su apreciación histórica como en su adecuación, antes de su ingestión, también lo es su valor energético, aunque nada sabemos acerca de los componentes sociales de éste en términos de códigos, valores y símbolos. ${ }^{14}$

\section{CuAdro 5}

VALORES ENERGÉTICOS ALIMENTICIOS DE LA RACIÓN MEDIA DIARIA: OCTUBRE (1909) - MAYO (1910)

(kcal)

\begin{tabular}{lrrrr} 
ALIMENTOS & PRÓTIDOS & \multicolumn{1}{c}{ LíPIDOS } & \multicolumn{1}{c}{ GLÚCIDOS } & \multicolumn{1}{c}{ TOTAL } \\
\hline Arroz & 9,7597 & 0,9718 & 117,8765 & 128,6080 \\
Cebollas & \multicolumn{1}{c}{0,4173} & 0,1791 & 4,2401 & 4,8370 \\
Aceite & \multicolumn{1}{c}{} & 7,4256 & - & 7,4250 \\
Manteca & - & 449,4666 & - & 449,4660 \\
Carne (I) & 248,6908 & 158,8233 & - & 407,5140 \\
Carne (II) & 389,9970 & 249,0666 & - & 639,0640 \\
Carne (III) & 303,3331 & 193,7198 & - & 497,0530 \\
Panela & - & - & 623,5685 & 623,5690 \\
Plátano & 21,6384 & 7,7004 & 602,7588 & 632,0976 \\
Maíz & 203,4669 & 293,4522 & $2.494,7312$ & $2.991,6503$ \\
Ajos & 0,5560 & 0,0669 & 3,9475 & 4,5744 \\
Frijoles & 1,4852 & 0,1741 & 4,1640 & 5,8230 \\
Topochos & 4,2672 & 8,2026 & 96,5844 & 109,0542 \\
\hline TotAL (I) & 390,2815 & 926,4626 & $3.947,8710$ & $5.364,6100$ \\
ToTAL (II) & 631,6877 & $1.016,7059$ & $3.947,8710$ & $5.596,1600$ \\
TotAL (III) & 544,9238 & 961,3591 & $3.947,8710$ & $5.454,1500$
\end{tabular}

Fuente: Tabla II.

13 No es posible examinar los efectos de estas deficiencias por ausencia de observaciones sobre el estado de salud de los trabajadores en la documentación, aunque no parecen relevantes.

14 En entrevista a Mario A. Briceño, ex-administrador de hatos, San Cristóbal, marzo de 1985, éste describió la creencia común entre los llaneros de las décadas del 40 al 50 en áreas barinesas acerca de las propiedades afrodisíacas de la carne de toro, por lo que los trabajadores la evitaban. Ya se ha mencionado en este artículo el menosprecio de los adultos hombres a la leche y la mantequilla. 
En el cuadro 5, la cantidad total de calorías de los nutrientes ingeridos de las dos primeras raciones se ubica sobre los dos totales calóricos actualmente requeridos para trabajos de tipo 'muy activo' y 'excepcionalmente activo', ya señalados en el análisis anterior. De tal modo que, desde este ángulo, la ración media de ambos hatos podría considerarse apropiada.

La distribución porcentual de estas calorías entre los distintos componentes para las hipótesis I y II se presentan a continuación en el cuadro 6. Para evaluar la significación de sus dos fórmulas dietéticas, $[9,1$ - 17,3 $73,6]$ y [11,3 - 18,2 - 70,5], conviene compararlas con los aportes calóricos porcentuales recomendables en algunos estudios ${ }^{15}$ que establecen la fórmula:

$$
\text { [ } 10 / 13-25 / 30-58 / 65 \text { ] }
$$

Según los rangos de variación que en ella se establecen, las raciones bajo estudio presentarían un déficit proteico y de lípidos en la hipótesis I y normalidad proteica y déficit de lípidos en la hipótesis II. En ambos casos habría un exceso de glúcidos.

Sin embargo, el aporte calórico de los lípidos estaría en las dos fórmulas dentro de proporciones poco adecuadas si se consideran estudios en los que se establece que las grasas deben aportar de un $20 \%$ a un $30 \%$ de las calorías diarias. ${ }^{16}$ En todo caso, se advierte que las limitaciones proteicas y lípidas tendían a ser compensadas con el mayor consumo de glúcidos. No obstante, es difícil establecer qué fórmula fue la más probable, aun cuando es posible presumir que en los hatos examinados la segunda pudo haber estado vigente si se considera el sesgo de sobrevaluación del número de días-hombre de trabajo.

Con todo, la misma variabilidad de estos datos sugiere la hipótesis de que el problema central de la ración media de los hatos en la región pudo haber sido el de un equilibrio inestable entre proteínas y glúcidos. El examen de la actividad económica interna de estos hatos en 1909-1910, aporta más antecedentes. El funcionamiento de éstos requería rebajar los gastos de comida por medio de la producción propia de alimentos, de la que las cuentas de gastos/ingresos dan sólidas evidencias. En los glúcidos, el 97\% de las calorías de las dos raciones provenían de los plátanos, panela, maíz

15 Bengoa, J. M.: "Calorías, una visión de conjunto", en CAVENDES Fundación: La nutrición ante la crisis, pág. 331.

16 Camejo, Germán: “Alternativas nutricionales en el consumo de grasas”, ibídem, pág. 299. 
y topochos, con un peso relativo del maíz del orden de un $63 \%$, productos todos que eran cultivados y procesados dentro de los hatos. Este último producto contribuía con un alto porcentaje de proteínas vegetales, siendo la proporción de las de origen animal de un $51 \%$ y $62 \%$, respecto al sub-total de la sumatoria de ambas. Lo que al parecer, era satisfactorio en tanto actualmente se señala como un valor de complemento deseable un $57 \% .{ }^{17}$ La composición de las grasas tenía como característica la presencia de lípidos vegetales junto a los de origen animal, lo que seguramente proporcionaba contenidos en ácidos grasos esenciales. La adaptación de la ración media a las condiciones económicas de los hatos se advierte, finalmente, en que la panela, plátanos, maíz y topochos tenían un peso del $81 \%$ y $78 \%$ en el total de calorías alimenticias, en ambas hipótesis respectivamente.

\section{Cuadro 6}

ESTRUCTURA DE VALORES ENERGÉTICOS ALIMENTICIOS DE LA RACIÓN

MEDIA DIARIA: OCTUBRE (1909) - MAYO (1910)

(porcentajes)

\begin{tabular}{lcccccccc} 
& \multicolumn{2}{c}{ PRÓTIDOS } & \multicolumn{2}{c}{ LíPIDOS } & \multicolumn{2}{c}{ GLÚCIDOS } & \multicolumn{2}{c}{ TOTAL } \\
ALIMENTOS & $I$ & $I I$ & \multicolumn{1}{c}{$I$} & \multicolumn{1}{c}{$I I$} & \multicolumn{1}{c}{$I$} & $I I$ & \multicolumn{1}{c}{$I$} & $I I$ \\
\hline Arroz & 2,5 & 1,5 & 0,1 & 0,1 & 3,0 & 3,0 & 2,4 & 2,3 \\
Cebollas & 0,1 & 0,1 & 0,0 & 0,0 & 0,1 & 0,1 & 0,1 & 0,1 \\
Aceite & - & - & 0,8 & 0,7 & - & - & 0,1 & 0,1 \\
Manteca & - & - & 48,5 & 44,2 & - & - & 8,4 & 8 \\
Carne (I) & 50,7 & - & 17,1 & - & - & - & 7,6 & - \\
Carne (II) & - & 61,7 & - & 24,5 & - & - & - & 11,4 \\
Panela & - & - & - & - & 15,8 & 15,8 & 11,6 & 11,1 \\
Plátano & 4,4 & 3,4 & 0,8 & 0,8 & 15,3 & 15,3 & 11,8 & 1,3 \\
Máiz & 41,5 & 32,2 & 31,7 & 28,9 & 63,2 & 63,2 & 55,8 & 53,5 \\
Ajos & 0,1 & 0,1 & 0,0 & 0,0 & 0,1 & 0,1 & 0,1 & 0,1 \\
Frijoles & 0,3 & 0,2 & 0,0 & 0,0 & 0,1 & 0,1 & 0,1 & 0,1 \\
Topochos & 0,9 & 0,7 & 0,9 & 0,8 & 2,4 & 2,4 & 2,0 & 1,9 \\
\hline Total (I) & 100,0 & - & 100,0 & - & 100,0 & - & 100,0 & - \\
& $(9,1)$ & & $(17,3)$ & & $(73,6)$ & & $(100,0)$ & \\
Total (II) & - & 100,0 & - & 100,0 & - & 100,0 & - & 100 \\
& & $(11,3)$ & & $(18,2)$ & & $(70,5)$ & & $(100,0)$
\end{tabular}

Fuente: Cuadro 5

17 Guerra, Maritza: “Alternativa nutricional deseable de proteínas”, ibídem, pág. 294. 
Así, en la perspectiva de las calorías alimenticias —y más allá de la relativa normalidad puntual de su balance- es probable que los problemas de la alimentación no radicasen en las cantidades calóricas en sí, sino en el hecho de que la calidad nutricional pudo haber estado reducida a los mínimos exigibles para el mantenimiento de los niveles de actividad física en las tareas de los hatos. Aun cuando debe considerarse la posible ingestión de porcinos en el consumo de carne, de cuya crianza hay pruebas en la documentación, siendo poco factible que éstos sólo se destinaran a la provisión de manteca.

Dejando de lado una evaluación pormenorizada de los micronutrientes por sus obvias dificultades desde un ángulo histórico, la evidente monotonía del régimen alimenticio tenía implicaciones respecto a la calidad de la dieta. Todo indicaría que el patrón carne-panela-plátano-maíz, era la clave de los equilibrios orgánicos básicos. Sólo en términos de calorías alimenticias el $97 \%$ de los prótidos, el 54\% de los lípidos y el 94\% de los glúcidos provenían de estos cuatro productos, en la hipótesis de consumo más probable. Si éstos proporcionaban el $87 \%$ del total calórico alimenticio, bien podría afirmarse que la alimentación de los hatos dependía de ellos.

La estrecha relación de este patrón alimenticio y nutricional con la actividad económica interna de los hatos, en verdad, era un resultado estructural de un proceso evolutivo de larga duración en el cual estaban presentes elementos conformativos propios a las condiciones históricas de surgimiento del hato llanero. Éste se originó en la segunda mitad del siglo XVII a partir de un proceso de asentamiento territorial de empresas itinerantes de caza de ganado e indígenas. Verdadero proceso filogenético, tal territorialización fue posible sólo cuando en la división regional del trabajo surgió la actividad agrícola en el interior mismo de las unidades de producción ganadera. ${ }^{18}$

El limitado número de productos componentes de la dieta añade nuevos aspectos al problema de su calidad nutricional. Considerando la hipótesis II, por ejemplo, estos cuatro productos contenían hierro en un $91 \%$ y la carne sólo en un $22 \%$. Si se tiene en cuenta que este micronutriente es de más fácil asimilación en la carne que en los vegetales, la predilección llanera por este producto, además de ser una preferencia cultural, era un

18 Esta hipótesis sobre el origen del hato en los llanos venezolanos se encuentra desarrollada en: Torres S., Jaime: Evolución de la economía ganadera de los Llanos Centro-Occidentales. El Alto Apure en 1910. Renta y ganancia en 'El Caimán'y 'La Balza', Universidad de los Andes, Venezuela, 1990, inédito. 
imperativo nutricional. La vitamina $\mathrm{A}$, tiamina, riboflavina y niacina dependían de esos cuatro alimentos en un $98 \%, 93 \%, 95 \%$ y $76 \%$, respectivamente. En las condiciones de una ración basada en muy pocos productos, la calidad nutricional era la resultante de un equilibrio que se establecía sobre condiciones precarias. Variaciones en la cantidad de algunos alimentos podían afectarla sustancialmente. En tanto la oferta de panela, maíz y plátanos podía estar afectada por condiciones climáticas, organizativas y económicas, el único alimento básico seguro era la carne. De ahí la importancia que el trabajador llanero le asignaba en la dieta diaria. Su presencia y la monotonía de la dieta eran garantía de equilibrio nutricional.

La hipótesis III permite algunas conjeturas sobre el significado histórico de esa ración media en el área más vasta de los llanos centro-occidentales, en tanto las bases de ese cálculo reflejan mejor lo que podría haber sido la aportación cárnica de sus reses y se acepta la monotonía de la dieta como dependiente de las condiciones ecológicas de esa región. ${ }^{19} \mathrm{Su}$ fórmula dietética [10 - $18-72$ ] indicaría una normalidad proteínica en el rango mínimo, junto con un exceso de glúcidos y un déficit de lípidos, dependiendo las calorías alimenticias en un $87 \%$ de la carne, panela, plátano y maíz. Estas conjeturas sugieren la hipótesis, a explorar empíricamente, de un desequilibrio glúcidoproteico como posibilidad presente en la alimentación de los hatos de la región llanera. Una observación de mediados del siglo XIX, por ejemplo, señala que los llaneros no consideraban como esencial el "pan", comiendo en su reemplazo hígado cocido, "que les agrada más". ${ }^{20}$ Podría considerarse como una práctica correctora de cierto déficit de glúcidos vegetales.

La posibilidad de un desequilibrio alimenticio potencial es tanto más probable si se considera que el gasto en carne se restaba al volumen total de la renta-producto anual y su equivalente en ingresos monetarios. La estabilidad de los salarios nominales, ${ }^{21}$ sugeriría que el eje conflictivo prin-

19 En 1906 un observador señala los rasgos comunes de la comida en la región llanera y su continuidad histórica cuando afirma que "Las plantas básicas de la alimentación llanera fueron, desde los primeros tiempos, el maíz, la yuca y el banano... He ahí nuestra base alimenticia: carne, leche y sus productos; menestra, maíz y sus compuestos, plátanos y yuca", González, Eloy G.: "El banquete llanero," El Cojo Ilustrado, Caracas, núm. 354, 15 de septiembre de 1906, págs. 570 y ss.; y núm. 355, $1^{\circ}$ de octubre de 1906, pág. 610. Publicado en Lovera, José R.: Historia de la alimentación en Venezuela, Caracas, 1988, documento núm. 45.

20 Páez: Escenas... , págs. 47-48.

21 Informaciones procedentes de entrevistas realizadas a trabajadores de toda la región llanera sugieren estabilidad salarial hasta la década del 30 de este siglo. Ver Carvallo: El hato..., pág. 32. El salario en dinero era sólo parte de la remuneración total, no existiendo estrictamente un mercado de mano de obra. 
cipal entre dueños de hato/peones llaneros podría haber estado precisamente en torno a las distintas presiones ejercidas sobre la alimentación y sus consiguientes efectos en el equilibrio de la dieta. En efecto, en la estructura de gastos de los hatos estudiados, los egresos por 'Alimentación', 'Operaciones' y 'Salarios' eran del $18,6 \%, 26,8 \%$ y $54,5 \%$, respectivamente. ${ }^{22}$ Considerados estos dos últimos rubros como costos fijos por hombre, y dadas las condiciones de estabilidad del salario nominal y del utillaje de trabajo, la única posibilidad de restringir los egresos monetarios de los hatos radicaba en la compresión de los desembolsos en alimentos. Por ello, el administrador debía producir internamente los productos de la dieta diaria y/u obtenerlos a bajo precio de economías campesinas cautivas. Una regla de buena administración era precisamente proveer al desarrollo de esta actividad agrícola. ${ }^{23}$ En ausencia de tales soluciones o de mal manejo de ellas, la tendencia habría sido disminuir la alimentación y/o rebajar su calidad. Si a ello se contraponía la capacidad negociadora de los peones, por la relativa escasez de mano de obra especializada, el conflicto era una posibilidad dada la lógica económica de los hatos.

Es posible, por tanto, que en la evolución histórica de los hatos apureños, como en el resto del llano, hubiera variado muy poco el régimen de alimentos, basado en el patrón carne-plátano-panela-maíz, dentro de los cambios experimentados por el régimen de nutrición, o balance total de valores energéticos que confluían para mantener las capacidades orgánicas de los habitantes de la sabana, tanto dentro de los hatos como fuera de ellos. Las limitaciones de la ración alimenticia presentada se compensaban en medida variable, seguramente, con el alimento ingerido fuera del lugar de trabajo. Algunas de estas limitaciones pudieron ser temporales. Si la documentación no presenta evidencias de consumo y producción de queso, es posible que ello se haya debido a la inestabilidad organizativa, resultado del embargo jurídico ordenado por el Gobierno. Tales alimentos eran tradicionales en la mesa llanera y un testigo afirma su incorporación habitual al almuerzo hacia $1935 .{ }^{24}$ Para esta fecha, sin embargo,

22 Ver Tabla IV.

23 El depositario general de los hatos en carta al administrador señalaba: "Queda autorizado para matar y para vender el ganado de que me habla y para limpiar y moler las cañas. Proceda en todo como si fuera suyo, como lo haría un buen dueño... Limpie los topochales y lo demás que haya que limpiar", RPSC, Civil, 1910, legajo "Cuentas de la administración de los Hatos El Caimán y La Balza", fs. 34-35 v. , San Cristóbal, 26 de octubre de 1909.

24 Rojas, J. César : entrevista del 15 de junio de 1986. Hacia 1846 Páez: Escenas... , pág. 48 , constataba que el queso era "un artículo predilecto". 
dicha fuente señala la larga permanencia de los trabajadores en el hato sin acudir a sus hogares.

Probablemente, el equilibrio alimenticio final requería que los trabajadores combinaran su actividad de trabajo con la caza, pesca y recolección o, directamente, con la siembra, en el caso de aquéllos que tenían acceso a tierras. En este sentido, la estacionalidad de la contratación podría haber permitido re-encontrar los balances vitales perdidos en los momentos de trabajo dentro de los hatos. En fuentes cualitativas se menciona a menudo la existencia de alimentos de caza, pesca y recolección de frutas como habituales en la comida regional. Para los peones de los hatos estudiados, sin embargo, la fruta no era apetecible. ${ }^{25}$

No obstante los rasgos apuntados como generales en la alimentación llanera, hubo probablemente diferencias en la alimentación apureña debidas, quizás, a las mejores posibilidades ecológicas para la ganadería y la agricultura en esta región. Existen evidencias de que en Apure, a mediados del siglo XIX, la alimentación habitual era bastante variada y que en los hatos se acudía más a los recursos silvestres proporcionados por el medio. Es la impresión que dejan las observaciones de Ramón Páez cuando, visitando esa zona señalaba que, como producto de la habilidad de los llaneros en la cocina, la carne asada se complementaba con abundante pescado cocinado de muchas formas y en pleno Apure, Mata Gorda, "la caza era muy abundante, y en todo tiempo se podía contar con ella" ${ }^{26}$ El medio físico presentaba una variedad de elementos alimenticios que permitían una dieta balanceada.

Tales observaciones sugieren la posibilidad de una disminución de la calidad nutricional de la dieta llanera en Apure durante la segunda mitad del siglo XIX. Si ello hubiera ocurrido, la estabilidad de las poblaciones en torno a las actividades de los hatos podría haber estado acompañada de dificultades crecientes para mantener sus equilibrios orgánicos. En tal caso, la hegemonía y estabilidad de la economía de los hatos apureños, con posterioridad a la década de los setenta del siglo XIX, podría haber sido correlativa a la disminución de las actividades de autosubsistencia. Tal asociación estaba implícita en la lógica económica de la generación de la renta ganadera, pues la provisión oportuna de mano de obra, en condiciones de

25 Rojas, entrevista citada, es enfático respecto al no consumo de fruta. Esto sugiere que no sea seguro que las listas de frutas silvestres disponibles en la ecología llanera, y reseñadas por muchos observadores, correspondieran a un consumo generalizado entre los peones.

26 Páez: Escenas..., págs. 76-77 y 238. 
escasez de ésta, requería de la creación de condiciones adecuadas para su oferta a bajo costo. ${ }^{27}$

La ausencia de observaciones e investigación sobre la variabilidad de la dieta en el tiempo y en el espacio es característica también de la diferenciación entre distintos grupos de edad. A mediados del siglo XIX, Ramón Páez señalaba que la leche y la mantequilla eran considerados "como alimentos sólo propios para niños", lo que indica que estaban reservados a ellos, ${ }^{28}$ pero no se dispone de más información respecto a la alimentación infantil y de las mujeres embarazadas.

A la luz de las consideraciones anteriores, parecería sorprendente que en un área como la del Alto Apure, situada en una región incorporada tarde a la explotación ganadera - la ocupación de sus territorios sólo se completó en los primeros decenios del siglo XIX - el promedio de consumo per cápita de carne en algunos de sus hatos no haya sido más alto, al tenor de las observaciones usuales hechas sobre la dieta llanera y su riqueza pecuaria. Y es poco probable que tales promedios hayan sido sustancialmente distintos en otros hatos de la región pues, en último término, una alimentación aprobada por los peones era factor de estabilidad en la captación de mano de obra. No obstante, debe notarse que el comportamiento social peonil era muy complejo. En general, era una mano de obra disciplinada y frugal: "Escasamente equipados, pagados pobremente, y con la sencilla comida de los Llanos por ración, siempre acuden a toda hora allí donde los llama el deber". ${ }^{29}$ Sin embargo, era característica su extrema susceptibilidad "al punto de no tener en cuenta consideración alguna... cuando dice me voy, para sobre la marcha esfumarse sin siquiera esperar a ser sustituido, en la seguridad de encontrar colocación en el hato vecino o en el de más allá". ${ }^{30}$

Por último, un problema importante para el manejo económico de la mano de obra y sobre el cual no se dispone de datos precisos es el relativo a la estrecha relación entre sal y estimulantes alcohólicos y no alcohólicos.

27 El hato condicionó la constitución de economías de subsistencia dentro de los límites espaciales y económicos de su funcionamiento por medio de la creación de economías campesinas cautivas y a través de los vínculos de paternalismo/deferencia con sus habitantes. De ahí que los buenos conocedores del llano señalaran la importancia de incorporar agricultores y 'vecinos' dentro de los hatos "para obtener éxito y realizar labores de íntima extracción llanera.... [no basta la remuneración]...porque en el llano, tanto como la buena paga y quizá más, va aparejada la voluntad de servir mejor, por el deber de compañerismo, compromisos de parentesco, compadrazgo, vecindad...", Calzadilla Valdés: Por los llanos ..., págs. 248-249.

28 Páez: Escenas..., pág. 48.

29 Ibídem, pág. 287.

30 Calzadilla V.: Por los llanos... , pág. 214. 
Se ha sostenido también que el alto contenido en sal de la dieta colonial explicaría el gran consumo de chocolate y guarapo. ${ }^{31}$ Es probable que la gran utilización de panela como bebida esté asociada con el consumo de sal en estos hatos, pero como ésta se empleaba también en la alimentación del ganado, no ha sido posible discernir el margen de consumo humano.

En resumen, puede concluirse que los datos examinados permiten apreciar una diferencia significativa entre la alimentación habitual para los trabajadores de hatos y aquélla percibida por los observadores contemporáneos sobre la alimentación llanera. Los 425 gramos medios netos diarios per cápita no avalan las imágenes de una dieta excepcionalmente rica en carne, sobre todo si se considera el esfuerzo físico que demandaba el 'trabajo de llano' y el carácter esencialmente ganadero de la economía. Sin embargo, parecen bastante más altos que el promedio de 150 gramos diarios per cápita de la población consumidora de carne en la Venezuela de $1873 .{ }^{32}$ El total calórico diario dependía en lo fundamental de una dieta vegetal y de muy pocos productos. A comienzos del siglo XX, tal régimen de alimentos en los hatos estudiados del Alto Apure reproduce los caracteres básicos del régimen advertido por observadores en la alimentación venezolana del último tercio del siglo anterior: débil importancia de la carne y mayoritaria aportación calórica de vegetales, aunque con una menor oferta de productos. Es particularmente claro al respecto la existencia del patrón carne-panela-plátano-maíz.

Nutricionalmente la dieta presentaba un mínimo proteico aceptable, una deficiencia en lípidos, exceso en glúcidos y una cantidad total de calorías alimenticias diarias adecuada a los requerimientos nutricionales actuales para trabajos de similar intensidad. Ello proyecta un desequilibrio glúcido-proteico potencial en la sociedad de los hatos que podría tener explicación en la particular lógica económica de éstos.

Tales patrones alimenticios y nutricionales pudieron ser el resultado de la particular génesis de la división regional del trabajo en el siglo XVII, dentro de la cual se explica el surgimiento del hato. Ello pone de relieve no sólo los imperativos ecológicos presentes en esta dieta, sino también el particular desarrollo histórico de esta economía en un ámbito más vasto. Frente a la precariedad de las condiciones que definían el equilibrio nutricional, la monotonía de la ración media era garantía de adecuación a los

31 Lovera: Historia de ... , págs., 81-82.

32 Torres S.: "Consumo de ....", pág. 69. Éste es un valor de una ración atribuida por los contemporáneos. 
requerimientos energéticos básicos, paradójicamente. Es decir, su papel decisivo en la aportación proteica era la base real que explicaba su importancia social.

Si el problema de los costos de los alimentos parece radicar en la dinámica reproductiva de los hatos estudiados y, por tanto, en el nivel de consumo de los peones, el equilibrio alimenticio final pudo tal vez depender de la continuidad de las actividades de caza, pesca y recolección. Una posible ración media regional podría haber sido menos monótona y más rica en nutrientes, aun aceptando su posible deterioro secular, en la medida en que pudo mantenerse la coexistencia de economías de subsistencia y hatos, en condiciones de irregularidad ocupacional de los llaneros de "caballo y soga'. Es decir, la proclividad peonil a la vida inestable y errabunda podría haber corregido, en cierta medida, desequilibrios glúcidos-proteicos potenciales en la vida de los hatos. Así, tal forma de vida pudo haber sido no sólo un ejercicio de 'libertad' o de vocación para la autonomía económica, sino también una exigencia imperativa de supervivencia. 


\section{TABLA I}

FORMAS DE PAGO DE LA MANO DE OBRA: 1909 - 1910

\begin{tabular}{lrcrr} 
& \multicolumn{3}{c}{ NÚMERO DE } & \\
& HOMBRES & DÍAS DE TRABAJO & SALARIOS \\
\hline POR DÍA & & & & \\
1. Peones de hato (a) & 48 & 1.351 & $\$$ & 698,25 \\
2. Corte de caña & 1 & 14,5 & $\$$ & 9,00 \\
3. Mesero & 10 & 273 & $\$$ & 159,00 \\
4. Pastoreo de marranos & 5 & 130 & $\$$ & 63,00 \\
5. Canoero & 2 & 62 & $\$$ & 12,00 \\
6. Servicio & 9 & 262 & $\$$ & 111,50 \\
\hline$\quad$ Sub-total & 75 & $2.092,5$ & $\$ 1.052,75$
\end{tabular}

POR TAREA

7. Viajes
I. Pueblo (b)
$22(\mathrm{c})$
15
$\$ 51,00$
II. San Cristóbal
2 (d)
30
$\$ 54,50$

8. Cojida

\begin{tabular}{lcrrr}
\multicolumn{1}{l}{ I. Animales } & $11(\mathrm{c})$ & 23 & $\$$ & 66,00 \\
II. Plátanos & $6(\mathrm{c})$ & 9 & $\$$ & 26,76 \\
III. Bejucos & 1 & 3 & $\$$ & 12,25 \\
Búsqueda y traslado de gente & 1 & 1 & $\$$ & 46,12 \\
Composición de corrales & 1 & 30 & $\$$ & 131,00 \\
\hline Sub-total & 44 & 111 & $\$$ & 387,63 \\
\hline TOTAL & $119[92(\mathrm{e})]$ & $2.203,5$ & $\$ 1.440,38$
\end{tabular}

Fuentes: RPSC, Civil, 1910, (2 bultos), legajo: "Cuentas de la administración de los hatos El Caimán y La Balza", fs. 8-9 v., documento 'Lista de peones desde octubre 4 noviembre 28 en El Caimán y La Vega o sea Santa Teresa', 28 de noviembre de 1909; fs.13-24, documento 'Cuentas que presenta Carlos Segundo Mora, de la administración de los hatos El Caimán y La Balza, como Depositario de ellos, San Cristóbal, junio 20 de 1910', documento 'Lista de los jornales que he pagado desde el 2 de octubre de 1909 hasta el 7 de mayo de 1910'.

(a) Incluye al caporal. (b) Probablemente Guasdualito. (c) Es probable que estos valores estén sobrevaluados, pues se ha supuesto que las tareas indicadas en la documentación fueron realizadas por hombres distintos. (d) Seguramente uno de ellos es el encargado de los hatos. Éste no figura en la nómina de los pagados pues se le remuneraba con base a un porcentaje estipulado por los tribunales. No se le contabiliza en el total de hombres. (e) Esta cifra se obtiene restando al total los ítems 5, 7 y 9, es decir, el número de hombres que estaba ausente de las casas del hato cuando trabajaban. Corresponde la cifra, por tanto, a los hombres presentes en las comidas diarias.

Para calcular el consumo per cápita se utilizó un promedio de días-hombre de trabajo igual a 23,95, obtenido de la división del número de días de trabajo por el número de hombres que efectivamente estaban en el hato. 
TABLA II

COMPOSICIÓN DE NUTRIENTES DE LA RACIÓN MEDIA DIARIA: OCTUBRE (1909) - MAYO (1910)

\begin{tabular}{|c|c|c|c|c|c|}
\hline ALIMENTO & $\begin{array}{c}\text { CONSUMO NETO } \\
\text { MEDIO DIARIO } \\
\text { P/C grs. }\end{array}$ & $\begin{array}{l}\text { PRÓTIDOS } \\
\text { grs. }\end{array}$ & $\begin{array}{c}\text { LÍPIDOS } \\
\text { grs. }\end{array}$ & $\begin{array}{c}\text { GLÚCIDOS } \\
\text { grs. }\end{array}$ & CALORÍAS \\
\hline Café & 425,57 & 1,2767 & 0,4256 & 3,4046 & 8,51 \\
\hline Especies & 5,64 & - & - & - & - \\
\hline Arroz & 116,13 & 2,5549 & 0,1161 & 28,3357 & 128,90 \\
\hline Cebollas & 10,72 & 0,1501 & 0,0214 & 1,1042 & 4,50 \\
\hline Aceite & 0,84 & - & 0,8400 & - & 7,38 \\
\hline Manteca & 49,83 & - & 49,8300 & - & 449,47 \\
\hline Carne (I) & 270,89 & 58,2414 & 17,6079 & - & 406,34 \\
\hline Carne (II) & 424,81 & 91,3342 & 27,6127 & - & 637,22 \\
\hline Carne (III) & 330,41 & 71,0382 & 21,4767 & - & 495,62 \\
\hline Panela & 175,14 & 1,0510 & - & 161,1288 & 623,49 \\
\hline Plátanos & 459,98 & 6,4400 & 0,9200 & 167,4330 & 630,17 \\
\hline Maíz & 876,83 & 74,5300 & 35,0600 & 619,0400 & $2.989,90$ \\
\hline Ajos & 3,85 & 0,2000 & 0,0080 & 1,0280 & 4,20 \\
\hline Frijoles & 5,22 & 0,4280 & 0,0208 & 1,0231 & 6,00 \\
\hline Topochos & 97,56 & 1,2700 & 0,9800 & 26,8290 & 108,30 \\
\hline TOTAL (I) & & 146,1400 & 105,8300 & $1.009,3300$ & $5.367,20$ \\
\hline TotAL (II) & & 179,2340 & 115,8300 & $1.009,3300$ & $5.598,00$ \\
\hline TotAL (III) & & 158,9380 & 109,6900 & $1.009,3300$ & $5.456,40$ \\
\hline
\end{tabular}

Fuente: RPSC, Civil, 1910, legajo: "Cuentas de la administración de los hatos El Caimán y La Balza”, fs. 8-9 v., 13-24. Instituto Nacional de Nutrición: Tabla de Composición de Alimentos para Uso Práctico, núm. 50, Revisión 1994.

El 'consumo neto medio diario' se ha calculado a partir del peso neto de los alimentos dividido por el factor 23,95 y por el número de hombres. En la hipótesis I se utiliza un promedio de $66 \mathrm{~kg}$ de carne utilizable, es decir, el peso medio de una res menos cabeza, patas y rabo. Es el valor estimado por Sterling, Henry S. (coordinador): Problemas económicos y sociales de los Andes venezolanos, Caracas, 1955, pág. 136, única cifra obtenida por observación empírica sistemática a partir de una muestra de fincas en los Estados Táchira, Mérida y Trujillo. En la hipótesis II se utiliza un promedio de $103,5 \mathrm{~kg}$ de carne utilizable. Se basa en un peso medio por res de 18 arrobas (450 libras o $207 \mathrm{~kg}$ ) que corresponde a Guasdualito, según Días González, A.: El Táchira y el Alto Apure separados y unidos al mismo tiempo por la Selva de San Camilo, San Cristóbal, 1940, pág. 32, que era un buen conocedor del área. Coincide con Hernández: Tiempos idos..., pág. 81, quien señala un peso de 18 a 20 arrobas en los novillos apureños conducidos al Táchira o Barinas. Se aplica una media de carne utilizable de 50\% de acuerdo al Boletín de la Cámara de Comercio de Caracas, núm. 110, 1923, cifra también usada por Rangel, Domingo A.: Capital y desarrollo. La Venezuela agraria, I, UCV, 1975, pág. 94. En las hipótesis I y II se ha aplicado un factor de desecho para la carne de 1,2163, correspondiente al promedio de los de la "carne de res" y "vísceras de res". Para la hipótesis III se emplea un peso de 14 arrobas por 
animal, peso medio del ganado llanero de "escasa 'caja' y poco precoz", según Carvallo: El hato ..., pág. 69, quien estima que tenía de 13 a 14 arrobas a los 4 o 5 años, cuando estaba apto para la comercialización. Se emplea una cifra de carne utilizable del $50 \%$.

Para el cálculo de los valores nutritivos se utilizaron los siguientes alimentos: "arroz blanco cocido (sancochado)" (núm. 2); "maíz amarillo, arepa de" (núm. 23); "frijol cocido" (núm. 264); "cambur topocho" (núm. 358), con valor de 111 calorías; "plátano verde salcochado" (núm. 432); "café: infusión sin azúcar" (núm. 454); "manteca de cerdo" (núm. 485); "papelón negro" (núm. 506). Los criterios de selección fueron, primero, acercarse a las condiciones reales de la alimentación histórica y, segundo, considerar los caracteres de las raciones reales. Se eligieron los valores del maíz amarillo, por ejemplo, pues, según entrevistas, era el que comía la gente en Apure, y no el blanco, que se daba a los animales.

Para calcular el peso neto de la carne — que no figura en la presente Tabla — se utilizó el factor de desecho 1,2163, promedio de los factores para los distintos tipos de carne y vísceras, según valores del Instituto Nacional de Nutrición, Tabla de Composición de Alimentos para Uso Práctico, núm. 42, Revisión 1983. De esta misma publicación se emplearon los valores para 'carne magra' (núm. 101) para determinar la composición de nutrientes, por considerarse que sus conceptos se acercan más a la situación histórica analizada que los de la publicación núm. 50.

Para el cálculo de los valores energéticos alimenticios del cuadro 5 se utilizaron los siguientes valores Atwater, de la publicación núm. 42: para el arroz, "arroz blanco o pulido"; para la cebolla y ajo, "Otros cultivos subterráneos"; para el maíz, "Harina de maíz, molida entera".

\section{TABLA III}

\section{COMPOSICIÓN DE NUTRIENTES DE LA RACIÓN MEDIA DIARIA: OCTUBRE (1909) - MAYO (1910)}

\begin{tabular}{lrrccccc} 
AlimENTOS & CALCIO & HIERRO & VIT. A & TIAMINA & RIBOF. & NIACINA & VIT. C \\
\hline Café & 21,28 & 0,85 & - & 0,043 & 0,043 & 11,06 & - \\
Arroz & 15,10 & 0,70 & - & 0,080 & 0,020 & 1,86 & - \\
Cebollas & 3,65 & 0,04 & 0,54 & 0,003 & 0,004 & 0,02 & 0,97 \\
Carne (I) & 16,25 & 7,31 & - & 0,220 & 0,620 & 13,81 & - \\
Carne (II) & 25,49 & 11,47 & - & 0,34 & 0,980 & 21,670 & - \\
Carne (III) & 19,83 & 8,92 & - & 0,260 & 0,760 & 16,85 & - \\
Panela & 304,74 & 7,36 & - & 0,020 & 0,160 & 0,88 & - \\
Plátano & 27,59 & 2,76 & 869,36 & 0,320 & 0,280 & 3,22 & 41,39 \\
Maíz & 78,91 & 26,30 & 263,05 & 3,240 & 0,960 & 17,54 & - \\
Ajos & 2,00 & 0,05 & - & 0,008 & 0,003 & 0,02 & 0,40 \\
Frijoles & 1,31 & 0,12 & - & 0,090 & 0,003 & 0,02 & - \\
Topochos & 24,39 & 3,22 & 19,51 & 0,060 & 0,050 & 0,49 & 19,51 \\
\hline Total (I) & 495,20 & 48,71 & $1.152,50$ & 4,080 & 2,140 & 48,92 & 62,77 \\
TotAL (II) & 504,46 & 52,87 & $1.152,50$ & 4,200 & 2,500 & 56,78 & 62,27 \\
TotAL (III) & 498,80 & 50,32 & $1.152,50$ & 4,120 & 2,280 & 51,96 & 62,27 \\
\hline
\end{tabular}

Fuente: RPSC, Civil, 1910, legajo: "Cuentas de la administración de los hatos El Caimán y La Balza”, fs. 8-9 v., 13-24. Instituto Nacional de Nutrición: Tabla de Composición de Alimentos para Uso Práctico, núm. 50, Revisión 1994. 


\section{TABLA IV}

\section{RESUMEN DE LAS CUENTAS DE GASTOS DE LOS HATOS 'EL CAIMÁN' Y 'LA BALZA': OCTUBRE (1909) - MAYO (1910)}

\begin{tabular}{|c|c|c|c|c|}
\hline & CANTID & & & \\
\hline RUBROS & peso documental & Peso bruto $(\mathrm{kg})$ & & VALOR \\
\hline 1.-Alimentos & & & $\$$ & 492,50 \\
\hline Café & 81,54 (arrobas) & 937,71 & “ & 243,50 \\
\hline Especies & 27,00 (libras) & 12,42 & “ & 20,25 \\
\hline Arroz & 22,25 (arrobas) & 255,88 & “ & 55,75 \\
\hline Cebollas & 56,50 (libras) & 25,99 & “ & 13,50 \\
\hline Aceite de comer & 2,00 (litros) & 18,40 & “ & 2,50 \\
\hline Manteca & 6,00 (damasanas) & 109,80 & “ & 24,00 \\
\hline Carne & 198,00 (arrobas) & $2.277,00$ & “ & 一 \\
\hline Panela & $385,90 \quad(\mathrm{~kg})$ & 385,90 & “ & 53,25 \\
\hline Plátanos & 3000,00 (unidades) & $1.500,00$ & “ & - \\
\hline Vinagre & $1 / 2 \quad$ (botellas) & - & “ & 0,75 \\
\hline Maíz & 105,00 (almudes) & $1.932,00$ & “ & 71,50 \\
\hline Ajos & 22,50 (libras) & 10,35 & “ & 5,25 \\
\hline Frijoles & 1,00 (arrobas) & 11,50 & “ & 2,25 \\
\hline Topochos & 40,00 (arrobas) & 460,00 & “ & - \\
\hline 2.-Operaciones & & & $\$$ & 708,20 \\
\hline Hato & & & “ & 573,23 \\
\hline Casa & & & “ & 135,39 \\
\hline 3.-Salarios & & & “ & $1.440,38$ \\
\hline
\end{tabular}

Fuente: RPSC, Civil, 1910, legajo: "Cuentas de la administración de los hatos El Caimán y La Balza", fs. 13-24, documento 'Cuentas que presenta Carlos Segundo Mora de la administración de los hatos El Caimán y La Balza, como depositario de ellos. San Cristóbal, junio 20 de 1910'; “Cuenta de la administración del hato El Caimán, presentada por su Depositario Carlos Segundo Mora”, fs. 9-10 v.

En las fuentes sólo 11 reses eran "p'matar", "para el hato", "pa' la casa", es decir, para el consumo interno. Los marranos fueron vendidos. Se mencionan 90 arrobas de carne vendida las que, presumimos, provinieron de nueve reses "cojidas" expresamente para ese fin. Las equivalencias utilizadas son: para el café, arroz y frijoles, una arroba es igual a 11,5 kilogramos; para las especies, cebollas y ajos, una libra es igual a 460 gramos; para el aceite y manteca se utilizaron valores de densidad de 0,92 y 0,916, respectivamente; para la conversión de las damasanas, se establece que una es igual a 18,3 kg; para panela se acepta que una carga es igual a $96 \mathrm{~kg}$ o 192 unidades, y una lata de melado, $17 \mathrm{~kg}$; los plátanos se consideran de tipo 'artón' con un peso de $0,5 \mathrm{~kg}$ por unidad; y un almud de maíz es equivalente a $18,4 \mathrm{~kg}$ Para la carne ya se ha establecido que una res del Alto Apure pesaba 18 arrobas, unos $270 \mathrm{~kg}$. Estas equivalencias son el resultado de investigación documental, entrevistas, observación directa y análisis de publicaciones. 